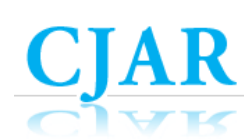

Canadian Journal of Action Research

Volume 20, Issue 2, 2020, pages 48-67

\title{
USING ACTIVITY WORKSHEETS TO REMEDIATE PRE-SERVICE TEACHERS' ALTERNATIVE CONCEPTIONS ABOUT WORD EQUATIONS
}

\author{
Ruby Hanson \\ The University of Education \\ Winneba, Ghana
}

\begin{abstract}
Worksheets hold the potential for providing active learning environments. This study describes the use of worksheet activities based on alternative concepts from a two-tiered diagnostic assessment on chemical phenomena to remediate 37 first year non-major chemistry pre-service teachers' alternative conceptions about word chemical equations in a Ghanaian institution. The instruments for data collection were tiered assessments and group learning conversations. The action research approach employed both qualitative and quantitative methods. Weaknesses in trainees' reasoning patterns were identified and remediated. A paired sample t-test showed significant differences in participants' conceptions before and after using the worksheets while the transcribed, analysed, and interpreted group learning conversation results corroborated the quantitative results. Implications for developing and using engaging and appropriate teaching strategies are offered.
\end{abstract}

KEYWORDS: Action research; Word chemical equations; Worksheets

\section{INTRODUCTION}

In traditional chemistry classrooms, students' prior conceptions are hardly challenged given they do not get the chance to express their learned conceptions in interactive sessions (Antwi, Hanson, Savelsbergh, \& Eijkelhof, 2011; Taber, 2002). Traditional classrooms are those where instructors make little or no use of interactive engagement (IE) methods, but rely primarily on passive-student lectures, recipe labs, and algorithmicproblem assessments (Hake, 1998). These traditional teaching methods are very common in most institutions (Antwi, Hanson, Savelsbergh, \& Eijkelhof, 2011; Hanson, 2017a). Often, 
teachers are burdened with time-bound curricula with terminal assessments and so do not have time for such academic extravagances and interactive-engaging lessons, as pertain in learner-centred classrooms (Anamuah-Mensah, 1989). In other words, teachers do not have time to develop learning experiences that respond to learners' questions or provide active experiential learning. However, for conceptual change and permanent learning to occur, an engaging learning environment would have to be created so that students would increase their understanding and ability to self-assess (Hanson, 2016; Posner, Strike, \& Hewson, 1982; Schmidt, Saigo, \& Stephans, 2006). They must be able to re-align, reorganise, and replace their non-scientific beliefs with logical, authentic, scientific ideas. In order for this change to occur, a cognitive conflict must be initiated by the teacher. Thus, science teachers could create learning situations where students can express their own concepts and allow them to be challenged with accepted views, through open discussions, worksheets, and other interactive activities (Chong, Salleh, \& AiCheong, 2013). Such activities can enhance students' understandings and prevent them from memorising scientific facts, such as chemical equations (which are too many) and from reproducing them by rote (Chandrasegaran, Treagust, \& Mocerino, 2009). Teachers could also engage learners in repetitive, context-based or inquiry lessons to enable re-alignment of scientific ideas. The environment or platform for identifying problems in students' reasoning patterns and planning a remediating action could best be done through a teacher's daily engaging activities with students or purposeful research.

Students, in general, are known to have problems with explaining chemical phenomena like chemical reactions and their representations with respect to different levels of matter, such as the microscopic, symbolic, and sub-microscopic levels (Chandrasegaran, Treagust, \& Mocerino, 2009; Chong, Salleh, \& AiCheong, 2013; Hanson, 2017b). Chemical equations are an essential part of a scientist's language. However, relating symbols and formula to chemical names, as well as writing full symbolic expression were identified as problems among tertiary pre-service teachers (herein referred to as trainees) in a study in Ghana (Hanson, 2017c). It was also found that the International Union of Pure and Applied Chemistry (IUPAC) nomenclature and other rules that governed naming of chemical species were not observed. There was an implication that the pre-service teachers had challenges with identifying and naming chemical compounds and needed remediation (Hanson, 2017b).

Chemical equations are expressed as word or formula equations. Formula equations enable students to check on numbers of atoms, ions, molecules or whatever species on the reactant and product sides of a chemical equation. The formula equation would be best for learners of chemistry, but the symbols seem quite abstract and so word equations are often introduced first to create 'reality' for learners (Taber, 2002). Examples could be:

1.Magnesium burns in oxygen to produce ....

2.What product(s) would be formed if formic acid from ants reacts with methanol from wood?

In this way, students become familiar with names or words and their various descriptions as the symbols change with respect to reactions with each other. Even in developing 
countries where tactile models and interactive approaches have been used, students' problems with symbolic representations remain (Taskin \& Bernholt, 2014).

For students, word equations relate better to macroscopic observations (as seen in practical activities), whereas the formula equations are based on molecular level representations where the application of the law of conservation is expected to be applied. Here, particles may be re-arranged, but new configurations should obligatorily reflect those in the old species. Students often have difficulties with making these analyses. Their difficulties become more apparent when their knowledge about the molecular and ionic nature of substances is required. With regard to word equations these demands are minimised on students. Though word equations do not require these mentioned mathematical or quantitative checks on conserving numbers of atoms, students have to remember certain principles which may be 'rule governed' and for which understanding and appreciation comes through practice. Students necessarily must identify with these principles so that categorisations can be established from observed patterns. For example, they are expected to know about some common types of reactions (such as that between say, an acid and a base), and products that could result from them. In this case, when such products are given to students to decipher their reactants, they would be able to do so with ease as they would have devised possible solution patterns from recurring events.

Contemporary educators try to help students to create their own authentic knowledge by integrating new experiences with existing knowledge. Educational reconstruction is one type of integration, where scientists' and novices' (learners') views are merged to strike a balance so that learners can accommodate scientific concepts with ease (Sam, Niebert, Hanson, \& Aryeetey, 2016). However, before integration, their naive ideas would have to be established. Thus, a favourable, interactive, and engaging (Hake, 1998) situation must be created to foster such a relationship that would enable participants to unveil their true ideas about phenomena. In the teacher training process, the objective must be not only to identify and correct teacher trainees' alternative conceptions, but it must also introduce them to new ways of diagnosing alternative conceptions and remediating them through innovative ways. Remediating identified alternative conceptions helps to break the cycle of misconceptions in academic communities. Worksheets have been found to be effective diagnostic teaching materials that could be employed in accordance with the constructivist learning theory to help students configure knowledge and at the same time participate fully in class activities (Celikler, 2010). This is because worksheets possess qualities that engage learners. These worksheets furthermore facilitate conceptual understanding through practice (Yildrim, Kurt, \& Ayas, 2011). This approach could be most applicable and useful in less endowed communities where the supply of electricity, technology, and other amenities are a challenge, as in Ghana.

Tiered assessments have also been found to be useful in identifying students' alternative conceptions more effectively than single-tiered multiple-choice items. Tiered assessments require that students express their ideas about chosen answers by giving reasons for their intended choices. These reasons are important as they provide evidence of students' reasoning structures and their depths of understanding (Hanson, 2016; Hanson, 2017a; 
Tan, Goh, Chia, \& Treagust, 2002). The appropriate environment for activities that reveal and build learners' conceptions, if they are erroneous, is best done by studying teaching and learning processes, using an action research design.

Action research is a process of systematic inquiry that seeks to improve social (classroom, school or curricular) situations that affect individuals (Stringer, 2008). It is cyclical, dynamic, and sometimes collaborative in nature while it enables researchers to develop inquiry approaches to study their own practices with an aim towards positive change in practice. A self-study approach was adopted in an in-class research with one's own teacher trainees because it provided room for improvement during teaching and learning and offered opportunity for continued reflection.

In an education action research environment, both teachers and learners make gains. These gains are possible because action research is participatory and offers many benefits for both teachers and learners alike, facilitating professional development and bridging the gap between research and practice (Holler \& Frabutt, 2012). It could include individual action research or school-wide research.

\section{FRAMEWORK FOR ACTION RESEARCH}

Action research in education is the process of studying a school situation to understand and improve the quality of the educative process that runs from day to day among learners and teachers (Johnson, 2012). According to Hine (2013) it helps in professional development because of its cyclical process. In this current study, an appropriate action plan and implementation based on Hine's proposition was developed for unearthing the participants' conceptual problems to correct them. Informal observation and semistructured interviews were chosen as part of the researcher's action plan in order to study a pervading teacher education situation and improve the quality of an educative process that could lead to new knowledge and understanding (Mills, 2011). The working plan is depicted in Figure 1.

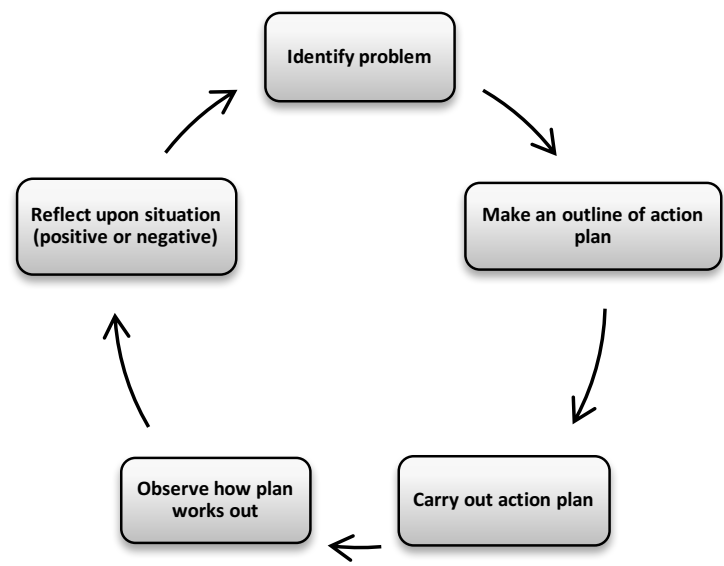

Figure 1: A cyclic working action research model

\section{PURPOSE OF THE STUDY}


The purpose of this study was to examine the conceptions that pre-service teachers hold about word chemical equations and offer remediation through the use of worksheets in an action research environment, to enable these pre-service teachers to deconstruct and restructure their naïve conceptions.

The main question that guided the study was:

1. What impact does a tiered worksheet approach have on pre-service teachers' conceptions about word chemical equations?

Other sub-questions were:

i) What conceptions about chemical equations would pre-service teachers exhibit on a two-tiered test in an analytical and reflective learning environment?

ii) What aspects of an activity worksheet would be suitable for building scientific conceptual gains about word chemical equations in a responsible reflective environment?

iii) What enhanced scientific conceptions would pre-service teachers demonstrate to show their understanding about expressing word equations?

\section{METHODOLOGY}

The study participants were 37 first year non-major Ghanaian chemistry pre-service teachers (herein called trainees) in a whole class study, whose consent were secured in accordance with the researcher's institution's Ethical Committee's policies. These trainees were undergraduates who had enrolled in teacher education courses upon graduating from high school (Grade 12). In the teacher training institution, these trainees study pedagogical and andragogical skills for their internship and future classroom activities. A case study with an action research approach was adopted because it is devoted to solving identified problems in given situations, promises to contribute towards optimising teacher education practices, fosters teacher competencies in evaluating pre-service teachers, and contributes to one's own professional development. It also enhances the observation, analytical, reflective and deductive skills of the researcher and allows for in-depth study in a real-life context rather than sweep over the issue as in statistical survey (Hine, 2013).

These trainees are expected to teach integrated science, of which chemical equations is a major topic with extended applications in other science topics in secondary schools upon graduation. Thus, they must have sound concepts and professionally developed pedagogies to teach effectively. Developed diagnostic worksheets based on the constructivist approach and Schmidt-Saigo-Stephan's conceptual model (2006), were employed to assess the trainees' pre-conceptions about chemical equations and help them reconstruct any anomalies. The worksheets were designed to present very common equations based on the principles of precipitation and solubility which students of chemistry encounter in practical laboratory analysis. They specifically worked on common school reaction types such as binary synthesis, displacement, neutralisation, and the action of acids on metals and carbonate. It was therefore expected that the trainees in this study would apply these principles in the second tier (reasoning part) of their answers. Again, the worksheet was designed to test trainees' knowledge about nomenclature and their proper expressions, but not to deliberately teach or test any sets of rules. 
The constructivist-paradigm model which was embedded in the design of the worksheets required trainees to take responsibility for their actions with justification. It was designed at least in part to engage trainees interactively with each other and the work materials, as well as to promote conceptual understanding through interactive engagement. Samples of test items and worksheets are shown as Appendices A, B1 and B2 respectively.

The action research framework was also embedded into the pre- and post-intervention tiered work for the trainees who were required to develop skills towards content and professional development. The worksheets were designed to inherently enable them to identify an assigned problem as well as their own self-learned challenges, acknowledge their existence, and attempt a plausible solution. These 'plausible' solutions had to be justified with tangible reasons. The important part of the exercise was this justification session, requiring them to explain logically, a solution that they had offered or their thought process.

Small group learning conversations were conducted in small focus group of six trainees per set. The 10-minute conversation sessions were content-focused. These were audiotaped, transcribed and analysed. The software for the transcription was the f5 transcriber and MaxQDA version II. A model of the small group learning conversation is shown as Appendix C. The guidelines were tested with trainees from another non-major chemistry class and modified appropriately.

\section{DATA COLLECTION PROCEDURE}

Data were collected in three stages - pre-intervention, intervention, and post-intervention stages. A two-tiered pre-intervention assessment that contained 10 items was administered. The test required trainees to write both word and symbolic equations for descriptions of chemical processes. The 2-tiered pre-intervention assessment was scored over 20 marks, as each representation was given a full mark. A sample of the items is shown as Appendix A. The scored marks were later translated into percentages. The developed activity worksheets, shown as B1 and B2, were used as intervention materials for 2 hours per week for three weeks, in accordance with the institution's timetable. A postintervention assessment was comprised of similar items as those used for the preintervention, which was administered much later, at the end of their semester.

The group conversations which followed guidelines based on content were audiotaped, transcribed, and analysed with the f5 transcriber and MaxQDA version II. Samples of learning conversation items are shown as Appendix C. The oral questions were used to focus the researcher's assessment for, as, and of the trainees' learning about chemistry.

These questions guided the assessment for, as, and of learning about chemical equations:

- How do trainees generally express chemical equations?

- How do they consider the law of conservation in chemical reactions?

- How do they express equations to depict an application of the law of conservation?

- Did they show connections between the macroscopic and particulate levels of matter in their arguments?

The Canadian Journal of Action Research. Volume, 20, Issue 2 (2020), 48-67 
- How useful was the tiered activity worksheet in exposing trainees' strengths, challenges, and weaknesses as they described chemical reactions in various forms?

- What conceptions did trainees come up with in their worksheet activities?

- To what extent was the action research able to unearth trainees' conceptions, and deconstruct their naive conceptions, in order to reconstruct scientific ones?

- What kinds of learning skills were developed and how?

Some unedited excerpts from a guided learning conversation are shown (TG = Trainee Group and $\mathrm{R}=$ Researcher):

R: Supposing trioxonitrate $(\mathrm{V})$ acid reacts with calcium carbonate, would that be possible?

TG2/6: Maybe. Not too sure since some reactants don't give products (pauses). Not sure

TG2/5: What is the first reactant again? .... (TG2 is informed) I do not know that too well. Mmm.... acid

R: Yes... nitric acid

TG2/2: Em .... Yes, it will be possible.

R: What products will result?

TG2/2: Calcium nitrate and water. A salt and water, as you will always get.

R: What are the basic constituents of the reacting species? Consider them.

TG2/1: Calcium, ......and carbonate.

R: Calcium is an element, but carbonate? Can we break it down into other components?

(Members remain silent)

Okay, let's get back to the products that would be formed from $\mathrm{HNO}_{3}$ and $\mathrm{CaCO}_{3}$

TG2/2: Salt and water

R: Why salt and water? Again, let's figure out the products more scientifically.

TG2/5: I know this one (smiles ....) Acid and other substances give salt and water.

R: Why these products?

TG2/1 and TG2/2: Acids often react to give salt and water.

TG2/3: No, only neutralisation reactions give salt and water and so here something else will result. Let me work it out .... (Trainee writes out equation using symbols) Calcium nitrate and $\mathrm{H}_{2} \mathrm{CO}_{3}$. It breaks down to give water. We don't do any practical activities so it's difficult to tell what happens sometimes. I can't really imagine .....It will should .... $\mathrm{H}_{2} \mathrm{O}$ and $\mathrm{CO}_{2}$

Further questions were asked about the 'nitrate' and how that name was arrived at, since hitherto other groups had intimated that the 'nitride' and 'nitrogen' could be obtained. A few unconventional names like 'nitrous' (which could have been learned from a teacher) came up. The answers that came up in these oral engagements were analysed interpretively and the causes of identified misconceptions assigned to categories such as vernacular, conceptual, factual, and preconceived misconceptions.

\section{DATA ANALYSIS}

In order to identify misconceptions and their possible causes, trainees' responses to oral and written questions were examined to find out if they conformed to scientists' expressions of scientific concepts. If the statements deviated from expected accepted scientific ideas or explanations, then the basis for their naïve, alternative or wrong answers 
were deciphered for an underlining cause. This was to find out whether the misconception emanated from the learner's own misconstrued interpretations, the home/community, culture, teachers, laboratory/classroom, language or otherwise. If the misconception had a bearing on local (ethnic or cultural) connotations, they were classified as 'vernacular'. For example, if there was a mix up with scientific terms such as melting, disappearing, and dissolving, because they meant one and the same in one's language and caused confusion for the trainee, then the misconception was classified as 'vernacular'. If the trainees' responses for justifications bordered on baseless unsupported facts, then they were deemed as conceptual misunderstanding, while suggestive folkloric underpinned answers were classified as preconceived ideas.

The pre- and post-intervention assessment scores were analysed using descriptive analysis for the first tiers only; after which the second tiers also were analysed interpretively. Preintervention test results are presented as Pre-tier 1 and Post-tier 1, while the postintervention results are presented as Pre-tier 2 and Post-tier 2 respectively in the Tables that follow. In tier 1, trainees wrote answers without reasons; while in tier 2 assignment reasons were required for answers from tier 1 . Trainees' analysed scores in the pre- and post-assessment are presented as Table 1.

Table 1

Trainees' analyzed scores in the pre-and post-assessment $(N=37)$

\begin{tabular}{lllll}
\hline Test & Mean & Standard deviation & T & p-value \\
\hline Pre-Tier 1 & 59.49 & 6.61 & -3.05 & 0.0016 \\
Post-Tier 1 & 66.03 & 11.26 & & \\
Pre-Tier 2 & 33.51 & 6.15 & -9.56 & $9.42 \times 10^{-15}$ \\
Post-Tier 2 & 54.78 & 12.05 & & \\
\hline
\end{tabular}

Pre-tier 1: Answers without reason before intervention; Pre-tier 2: Reasoned answers before intervention

Post-tier 1: Answers without reason after intervention; Post-tier 2: Reasoned answers after intervention

Paired samples t-test was used to assess the effectiveness of the worksheets and how they enhanced trainees' to conceptualise during the intervention stage. From Table 1, it is noted that trainees performed well in the first tiers of both the pre- and post-intervention assessments, but not in their second tiers (or reasoning parts). The t- and p-values obtained for the trainees' performance in the first tiers of the pre- and post-assessments suggest that trainees or students were likely to perform well in their first tiers, if they were allowed to make choices without having to analyse, reflect, or provide reasons, as required in second tiers. Making recall of facts, as often occurs in tier 1 depicts superficial acquisition of content knowledge and skills.

The mean scores for the second tiers of both assessments were quite low; $33.51 \%$ for the pre-assessment and $54.78 \%$ for the post-assessment. This could be interpreted to mean that how well or poorly one would perform in a second tier in a post-assessment cannot be

The Canadian Journal of Action Research. Volume, 20, Issue 2 (2020), 48-67 
predicted from one's performance in a $1^{\text {st }}$ tier assessment. The differences between trainees' performance in the $1^{\text {st }}$ tiers and $2^{\text {nd }}$ tiers of both tests were however all statistically significant $\left(\mathrm{p}=9.42 \times 10^{-15}\right.$, which translates to $\left.\mathrm{p}=0.00\right)$ for the postassessment and for the pre-assessment ( $\mathrm{p}=1.6 \times 10^{-3}$, which also translates to 0.00 ). Though both tiers show p-values of 0.00 , statistically, the p-value for the tier 2 assessments are statistically more significant than for the tier 1 assessments, which have a p-value of 0.0016. More correct answers were provided in the first tier of the post-assessment and were subsequently supported with correct reasons when compared with the preassessment.

The relationships between performances in the two tiers for each assessment (pre- and post-) were also determined. Pre-assessment mean scores are presented in Table 2.

\section{Table 2}

Pre-assessment mean scores for tiers 1 and 2 only

\begin{tabular}{llll}
\hline Pre-assessment & Mean & T & P \\
\hline Tier 1 & 59.49 & -17.5 & $1.26 \times 10^{-27}$ \\
Tier 2 & 33.51 & & \\
\hline
\end{tabular}

Pre-tier 1: Answers without reason before intervention; Pre-tier 2: Reasoned answers before intervention

From Table 2, it is observed that there is reduction in the mean value of trainees' assessments in Tier 2, implying that trainees performed more poorly in the second tier of the assessment (as observed from the mean values) because justifications for choices were required, as compared to the first tier where answers were given without justification. The statistical difference between the two tiers was $p=1.26 \times 10^{-27}$, so much lower than the set value of $\mathrm{p}<0.05$. The mean scores for the post-assessment only are shown as Table 3 .

Table 3

Mean scores for post-assessment tiers 1 and 2 only

\begin{tabular}{llll}
\hline Post-assessment & Mean & T & P \\
\hline Tier 1 & 66.03 & -4.15 & $4.55 \times 10^{-5}$ \\
Tier 2 & 54.78 & & \\
\hline
\end{tabular}

Post-tier 1: Answers after intervention; Post-tier 2: Reasoned answer after intervention

From Table 3, it is observed that trainees performed slightly better on making scientific justifications for answers given in their first-tier assessments in the post-intervention assessment than in the pre-intervention assessment (Table 2). Interpretive analysis of trainees' assessment data showed that their reasoning answers in tier 2 were more coherent and logical than in their pre-assessment where idiosyncratic reasons were given. The differences between responses (as shown by mean values) in the tiers narrowed down to 11.25 units apart, which was comparatively better and lower than the 15.98 units observed in the pre-test. The obtained p-value at a 95\% confidence interval, which was 
$4.55 \times 10^{-5}$ (i.e. 0.00) shows a significant difference between tiers 1 and 2; yet the difference, is not as significant as observed in the pre-assessment $\left(1.26 \times 10^{-27}\right)$ where very naive reasons were assigned, sometimes to correct responses in tier 1 . The implication is that the trainees gave more correct reasons for choices they had made in tier 1 of the postassessment. They appeared to have formed patterns by distinguishing between similar and different patterns of presentations from the reactions that were given to them. That is, they recognised and categorised reaction types into sets and so were able to figure out products that could be formed from certain common reactants as well as reactants that could be derived from certain given products. This proved true in their post-intervention assessment, where plausible reasons were given for answers/choices written.

Assumed equal variances for the entire assessments after the intervention was applied are shown in Table 4.

\section{Table 4}

A comparative analysis of the entire pre- and post-assessment scores

\begin{tabular}{llll}
\hline Assessment & Mean & $\mathrm{T}$ & $\mathrm{P}$ \\
\hline Pre-assessment & 33.51 & -9.56 & $9.42 \times 10^{-15}$ \\
Post-assessment & 54.74 & & \\
\hline
\end{tabular}

Table 4 confirms a significance difference between trainees' performance in the pre- and post-intervention assessments. Significantly improved progress was made by the trainees as the difference between their scores increased from their initial mean value of 33.51 to 54.74. This assertion is buttressed by a p-value of $9.42 \times 10^{-15}$ (or $\mathrm{p}=0.000$ ); a tremendous improvement in the trainees' abilities to express word equations and interpret them with understanding.

Analyses of the trainees' worksheets (in Appendices B1 and B2), that required them to show justification, revealed that they had diverse conceptions, which were naive and preconceived. They were unable to justify their answers based upon the different levels of representation of matter or relate them. Their application of the law of conservation of matter was misunderstood as numbers of atoms or species on the reactant and product sides of equations were not fully accounted for. In an exercise such as '......$+\ldots \ldots$. Barium sulphate + Copper'. A learner is expected to provide the same number of atoms or species on the reactant side $(\ldots . .+\ldots .$.$) with that observed on the product side (Barium sulphate +$ Copper), but in different compositions or units. Nonetheless, the fundamental numbers of elements must be equal on both sides to indicate that matter has been conserved. This was not observed.

The demonstration of learning skills and applications were lower than expected from learners in a tertiary institution. This assertion is made, because learners were expected to demonstrate higher order thinking and transferable skills in their reasoning and learning capabilities worthy of their ages. At the tertiary level, it is expected that learners can operate at the abstract level and demonstrate analytical reasoning. Some of the identified 
causes of trainees' misconceptions that were evident from analysis of their worksheets were:

1. Conceptual misunderstanding;

2. Factual misconceptions;

3. Vernacular misconceptions; and

4. Preconceived notions.

Assessment of the trainees' data showed that for every chemical reaction that involved a sulphate as a reactant, sulphuric acid was anticipated and written as a product, which was often not the case. A similar observation was made in cases where metal carbonates reacted with acids and any other reactant. Carbonic acid was always written as one of the resulting products. Wrong formulae were written because valences of atoms were wrong. Subsequently, oxidation numbers were wrongly worked out because valence numbers were wrongly applied. Some names of elements such as 'calcium' were spelt as 'calsium' and 'calscium'.

Some thematic alternative conceptions that were exhibited on the tiered assessments were:

1. Poor knowledge of reaction types and their possible resultant products;

2. Wrong presentation of chemical symbols;

3. Poor knowledge of valences, oxidation numbers, their derivation and application;

4. Inadequate knowledge of the principle of combining powers of elements;

5. Inadequate knowledge about;

7. Inappropriate names for products formed;

8. Inability to identify missing reactants and name them correctly if the products were supplied.

The above thematic alternative conceptions were helpful as they provided enough information for the researcher to relate to and also inform the interventive teaching. Each of the eight identified alternative conceptions suggest the weak foundation about chemical phenomena that the trainees had. For example, poor knowledge of valences and oxidation numbers is an indication of preconceived ideas. For students, all halogens must have an oxidation state of -1 , which is not always the case. Belief item 8 , is also an indication of conceptual misunderstanding.

\section{DISCUSSION}

The action research approach provided the researcher and the trainees alike with an analytical and reflective process. This process coupled with the activity worksheets was useful in revealing trainees' naive conceptions about chemical equations and how to express them in word form. It was observed upon analyses of the trainees' worksheets that it was often more difficult for them if they had to determine the reacting chemical species for given products and write them out correctly. It must be noted that these trainees were high school graduates (Grade 12) who had enrolled in a teacher education programme in Ghana. However, after a few class exercises, they were able to provide logical reasons for their answers. For example in the reaction: 
Magnesium + iron nitrate $\rightarrow$ magnesium nitrate + they were able to infer that iron would be the missing part because when a more reactive metal is added to a solution containing the salt of a less reactive metal, a reaction would occur.

Trainees' distinctive naive and erroneous conceptions were identified in the justifications that they assigned to responses in tier 1 of their pre-intervention assessments. For example, they intimated that all solutions contain 'salt' and 'water'. In chemistry, solutions can be formed from a mix of all the various states of matter - that is solid and liquid, liquid and liquid, liquid and gas, gas and gas, as well as gas and solid. Thus, ascribing a reason for a particular chemical outcome because it is a solution and contains salt and water is a preconceived notion and a misunderstanding about the nature of matter and its interactions. Some other wrong answers and reasons that were given were that iron (II) would be formed because the solution will be green' and 'this is the only ion that is green in solution'. The latter was a factual misconception. Some copper solutions could also appear green in some common reagents. The trainees demonstrated conceptual misunderstanding by offering some of these explanations. Some other questionable reasons were, 'the calcium salt that reacted was a hydroxide and so will yield no product'; no reaction will occur because calcium salts are insoluble'. These answers were given for a calcium salt that was reacting with aqueous hydrochloric acid. In the reaction with iron filings with sulphur, 'sulphide' was written by a few trainees as 'sulphis', 'sofii', and 'sulfis'. This was an interesting observation and a vernacular translation of sulphur. Other answers were 'ferric sulphide' and 'ferrous sulphide'. Iron (II) sulphide was produced by only a few of the trainees, some of who did not put the oxidation number in parenthesis.

In cases where the trainees were required to complete formula equations and translate their completed equations into word form such as: $\mathrm{Mg}+\mathrm{O}_{2} \rightarrow \ldots \ldots \ldots \ldots . . . . .$. , their weaknesses became more apparent. Their deficiencies about valences, oxidation numbers and balancing of chemical equations were exposed. They showed little understanding about IUPAC nomenclature and the principles that governed their expressions. MgO was expressed as magnesium (II) oxide, even though group 1 and 2 elements have fixed oxidation states and so their oxidation numbers are not indicated as a rule. Both magnesium and oxygen have oxidation magnitudes of two (2) and so balance out quite well as $\mathrm{MgO}$ (with +2 and -2 for magnesium and oxygen respectively) yet a few answers such as $\mathrm{Mg}_{2} \mathrm{O}$ and $\mathrm{MgO}_{2}$ came up with indescribable explanations as to why those answers were written. Some of the trainees giving these answers knew the correct oxidation numbers for the species in question but did not apply them in chemical formulas. Thus, it was clear that some of the trainees did not analyse or reflect upon their answers but need to be aware of such considerations as future teachers.

When the trainees were presented with similar reactions to solve and give reasons for their answers in a content-focused oral conversation session, it became evident that a few of them (about seven) still retained their innate misconceptions. These seven trainees' arguments were based on unstructured, illogical reasoning patterns. They continued to present wrong names of chemical products, especially where nitro compounds were 
involved in reactions. Their pre-existing conceptions continued to appear in their arguments. It was observed that they had difficulties in expressing chemical reactions in word-form because they basically required an understanding of the nature of chemical change, conservation of matter, as well as familiarity with chemical names and their spellings (Hanson, 2017a). More importantly, they required the knowledge of principles of compound formation, which could be obtained through associations and dissociations by observing or constructing patterns from recurring activities in order to form mental models about them. Thus, it appears that when topics are introduced when learners are not developed mentally or psychologically to handle them in abstraction they retain their misconceptions or develop other faulty conceptions. A typical example could be an instance where students are expected to write names and chemical formulae for compounds for which they have not mastered the symbolic representations of elements or radicals, their correct names, and proper spellings. In this study, the use of a sequenced worksheet activity in an analytical and reflective learning experience enabled the majority of trainees (24 out of 37) to start constructing 'reaction type' mental slots based on repetitive activities on word chemical equations, arguments raised among peers, and reflecting on their answers with justification before conclusions were formulated.

Their conceptual misunderstandings were found to be based upon their weak foundations of IUPAC nomenclature and rules that governed the different types of chemical reactions and their products such as:

Acids + alkalis resulting in salt and water;

Acids + metals resulting in salt and hydroxide;

Metal carbonate + acid resulting in a salt, carbon dioxide and water;

Metal sulphate + acid resulting in a salt, sulphur dioxide and water;

Metal + salt solution and its outcome; and those for reactions between nitrates, sulphides, sulphites, and other substances.

It was observed that if a product component was, for example, a 'nitrate', some trainees could not decipher that the starting material or reactant (if it had to be an acid) then had to be trioxonitrate (V) acid. Such rules could be perfected through constant practice and hands-on activities. They had the perceptions that all reactions resulted in only salt and water, yet failed to identify and name these salts with analytical and deductive reasons. Some answered that their products were salts because they were precipitates. Some responses were based on recall rather than from analysed parts of the chemical equations. For a particular reaction, a trainee intimated that both sides of the equation had to be equal but could not figure out the missing component on the reactant side. This problem implies that even though this trainee knew about the law of conservation, she could not apply it. She failed to figure out the possible products for the given reactants as she could not pattern it on any principle. The basic principle of conservation of matter was lost on the trainee and many others. In another case in the guided learning conversation session, a trainee in one of the groups exhibited apparent difficulties that centred on how numbers of atoms of some elements such as oxygen could be a determining factor in the name of a product that he was supposed to work out. 
It was obvious that after the intervention a few of the trainees could not distinguish among the names 'nitrogen', 'nitrile', 'nitride', and 'nitrate'. Coming up with an unconventional name like 'nitrous' would have been more difficult for them to comprehend in this situation. In one other group (TG 5), where a few trainees attempted to solve the word equations using the symbolic expression, they were asked what the name for a compound such as $\mathrm{Ca}\left(\mathrm{NO}_{2}\right)_{2}$ or $\mathrm{HNO}_{2}$ would be and they maintained nitrate, even when the actual nitrate formulas were presented to them. This implied that the said trainees still held on to their preconceived notions and factual misconceptions and so could not deconstruct them. Others said that the formulas were wrong. In this group the IUPAC name for $\mathrm{HNO}_{3}$ was challenged and so the oxidation number of nitrogen had to be worked out. It was evident that working out oxidation numbers for central atoms was one topic that had to be taught for clearer understanding of the guiding principles for working out oxidation numbers when IUPAC nomenclature is required.

The implication drawn from the trainees' responses was that some of them could not figure out appropriate names for missing compounds while a few made mistakes, even though they knew about the law of conservation of mass and how the number of oxygen atoms in species they affected their names. This challenge was observed when they had to name compounds with sulphur. They had to decide with difficulty whether they had a sulphide, sulphite, or sulphate. In most cases they opted for a sulphate, which they were more familiar with. In effect, they were not familiar with naming categories of chemicals (oxide, hydroxide, acid, -ate, -ide and ite). The seemingly simple principle of the law of conservation proved to be difficult for the trainees when confronted with its practical application.

The developed worksheets had the potential to expose trainees' naive conceptions about the principles of precipitation and solubility, particularly. They allowed trainees the freedom to express their innate beliefs about the nature of matter unassumingly, which is a constructive aspect of the worksheet activity (Celikler, 2010; Chong, Salleh, \& AiCheong, 2013). These worksheets also enabled them to participate actively in the learning process so that their performance improved in the post-assessment exercise. Repeating an activity using the same set of thinking capacities and skills strengthened connections between concepts. These connections were strong enough to build conceptual frameworks as each correct practice fortifies a conception to make it permanent (Hanson, 2017a). Furthermore, if trainees have challenges and conflicting issues with governing principles as they interact more with such exercises, it would expose their weaknesses such that they will let go their naive conceptions, discard them, and make way for the construction of more scientific principles upon reflection. These findings suggest that constructivist worksheets can help learners to configure concepts in their minds through association and dissociation by means of patterns, and thereby reduce conceptual errors (Hanson, 2017b).

The worksheets also were designed to encourage the trainees to reflect on their answers either before they provided them or after they had provided them (Schmidt, Saigo, \& Stephans, 2006) because of its tiered nature (Tan, Goh, Chia, \& Treagust, 2002). Thus, their reflective, analytical, and deductive skills, which are higher learning skills, were brought to 
the forefront. Besides, it enabled re-organisation of their naive ideas so that those ones were discarded upon being challenged. Then, more authentic concepts were constructed upon convinced beliefs.

It was expected that with their theoretical and laboratory experiences in their study of chemistry students would have formed authentic concepts about the formation or dissolution of solids during chemical reactions (Chandrasegaran, Treagust, \& Mocerino, 2009). However, this was not so, as revealed through the worksheets. Further practical laboratory activities (which are to be presented in a follow up paper) contributed to their macroscopic interpretation of chemical reactions because they were able to decipher among chemical reactions by recurring identification criteria like colour, the evolution of a gas, and other such discriminatory guides in chemistry. Nevertheless, by the end of the intervention period they were able to make logical and scientific justifications for answers that they provided in their second tiers, or wherever justifiable presentations were required. Their conceptual and vernacular misconceptions were reduced drastically as they were able to deduce with appropriate reasons, the missing parts of word equations correctly. Their spellings, analytical, discussion, and reflective skills also improved.

Evidence gathered and considered in this study suggests that the use of the worksheets in this action research study promoted reflective learning. The worksheets expanded the trainees' pedagogical repertoire for the future, while it reinforced the link between theories that they had learned, practice and their cognitive achievement, which were all fostered on their openness towards new ideas. In line with the constructivist paradigm, the worksheet activities gave the trainees ownership of the concepts that they acquired. The action strategy used in this study replaced the less effective teacher training used in the past which served as the means for professional development for the researcher (Johnson, 2012). It promoted empowerment as it was possible to implement practices that best meet the needs of trainees and complemented their individual talents, experiences and creative ideas in the classroom.

\section{CONCLUSION}

There was adequate evidence that action research was a valuable learning exercise to undertake with respect to unearthing and remediating pre-service teachers' understanding about word equations presented on worksheets. It was found that the trainees' deficiencies stemmed from non-performance of hands-on or engaging activities (Antwi, Hanson, Savelsbergh, \& Eijkelhof, 2011; Hanson, 2017a) for the development of processes of identification from recurring patterns or commonalities and distinctions in figuring chemical equations. The worksheets however proved to be useful in engaging the trainees more actively, as the t-test results revealed. The p-values were statistically significantly high, at a value of 0.000 . These worksheets exposed the misconceptions about how trainees understood and expressed chemical equations in word form because they required trainees to provide reasons for making decisions. Furthermore, this reasoning required them to reflect, analyse, deduce, and draw conclusions based upon their critical considerations as they chose answers. This level of thinking was found embedded in the reasoning (second tier) portion of the worksheet. In this way, the trainees' higher cognitive

The Canadian Journal of Action Research. Volume, 20, Issue 2 (2020), 48-67 
structures were revealed and used to build sounder conceptions than before, as revealed by their post-intervention assessment performance. This observation could be attributed to the engaging activities that invariably strengthened their cognitive connections so that they made significant gains in sound conceptions about word equations.

\section{IMPLICATIONS AND RECOMMENDATIONS}

Worksheets hold the potential to improve pre-service teachers' academic achievement and provide active learning environments. The adoption of action research methods improved teaching and learning in this particular self-study because it provided a rich reflective cycle for teacher improvement for the author. The use of worksheets could be extended to other difficult but worksheet-workable chemistry topics that trainees have misconceptions about. Worksheets need not be an everyday work tool. Its principle is designed to be a component of stepwise procedures to help learners achieve at levels they cannot reach without support. Worksheets could be a platform for the formation of new knowledge, allow for practice, familiarity, and give a feeling of success with new ideas that students can make their own. They can then be removed from among the teaching resources once they are no longer needed. In follow-up or related studies, the efficiency of worksheets could be compared with other instructional approaches.

\section{REFERENCES}

Anamuah-Mensah, J. (1989). A perspective on science education in Ghana. Ghana Association of Science Teachers, 14-15.

Antwi, V., Hanson, R., Savelsbergh, E. R., \& Eijkelhof, H. M. (2011). Level 100 Physics students' experiences and perceptions with imnteractive engagement in teaching: A study in a Ghanaian University. African Journal of Educational Studies in Mathematics and Sciences, 9(1), 14-35.

Celikler, D. (2010). The effect of worksheets developed for the subject of chemical compounds on student achievement and permanent learning. The International Journal of Research in Teacher Education, 1(1), 42-51.

Chandrasegaran, A. L., Treagust, D. F., \& Mocerino, M. (2009). Emphasising multiple levels of representation to enhance students' understandings of the changes occuring during chemical reactions. Journal of Chemical Education, 86 (12), 1433-1436.

Chong, V. D., Salleh, M., \& AiCheong, I. P. (2013). Using an activity worksheet to remediate students' alternative conceptions of metallic bonding. American International Journal of Contemporary Research, 3(11), 39-51.

Hake, R. R. (1998). Interactive-engagement versus traditional methods: A six-thousandstudent survey of mechanics test data for introductory physics course. American Journal of Physics, 66(1), 64-74. 
Hanson, R. (2016). Chemistry teacher trainees' perceptions of chemical equilibrium. The International Journal of Humanities and Social Studies, 4(1), 80-88.

Hanson, R. (2017a). Assessing the potential of worksheets as a tool for revealing teacher trainees' conceptions about chemical bonds. In C. A. Shoniregun, \& G. A. Akmayeva (Ed.), CICE-2017 Proceedings (pp. 648-653). Mississauga, ON: Infonomics Society.

Hanson, R. (2017b). Unearthing conceptions about types of chemical bonding through the use of tiered worksheets- A case study. International Journal for Cross-Disciplinary Subjects in Education, 8(12), 3112-3122.

Hanson, R. (2017c). Using activity worksheets to unearth 10th Grade studets' perceptions about word chemical equations. In A. Ismam (Ed.), International Teacher Education Conference. 2, (pp. 758-766). Cambridge, Boston, MA: Turkish Online Journal of Education and Technology.

Hine, G. S. (2013). The importance of action research in teacher education programs. Issues in Educational Research, 23(2), 151-163.

Holler, A. C., \& Frabutt, J. M. (2012). Mission driven and data in formal leadership. Catholic Education: A Journal of Inquiry and Practice, 15(2), 253-269.

Johnson, A. P. (2012). A short guide to action research (4th ed.). NJ: Pearson Education.

Mills, G. E. (2011). Action research: A guide for the teacher researcher (4th ed.). Boston: Pearson.

Posner, G. J., Strike, K. A., \& Hewson, P. W. (1982). Accommodation of a scientific conception: Toward of conceptual change. Science Education, 66, 211-227.

Sam, A., Niebert, K., Hanson, R., \& Aryeetey, C. (2016). Fusing scientists conceptual correspondences to improve teaching of metal complex isomerism in higher education- An educational reconstructive process. International Journal of Academic Research and Reflection, 4(1), 54-64.

Schmidt, D. L., Saigo, B. W., \& Stephans, J. I. (2006). Conceptual change model: The CCM Handbook. Missouri, USA: Saiwood Publications.

Stringer, E. T. (2008). Action research in education (2nd ed.). New Jersey: Pearson.

Taber, K. S. (2002). Chemical misconceptions-Prevention, diagnosis and cure. Volume 1: Theoretical background. London: Royal Society of Chemistry.

Tan, K. C., Goh, N. K., Chia, L. S., \& Treagust, D. F. (2002). Development and application of a two-tier multiple choice diagnostic instrument to assess high school students' understanding of inorganic qualitative analysis. Journal of Research in Science Teaching , 39, 283-301. 
Taskin, V., \& Bernholt, S. (2014). Students' understanding of chemical formula: A review of empirical research. International Journal of Science Education, 36(1), 157-185.

Yildrim, N., Kurt, S., \& Ayas, A. (2011). The effect of worksheets on students' achievement in chemical equilibrium. Turkish Science Education, 8(3), 44-58.

\section{BIOGRAPHICAL NOTE:}

Ruby Hanson is a senior lecturer and professor in Chemistry Education in the University of Education in Winneba, Ghana. She has taught various aspects of chemistry at various levels (both undergraduate and post graduate).Her research interests and contributions focus on graduate and undergraduate students in teacher education. 


\section{Appendix A \\ Abridged Pre- \& Post-Intervention Items}

Write formula equations for the reactions below (1-4) and write the names of the resulting compound. Explain why you formed your products of choice.

1. Trioxonitrate (v) acid reacts with aqueous calcium hydroxide.

From items 5-8, fill in the missing species and explain your answer

5. Zinc carbonate + $\rightarrow$ Zinc sulphate

I write this answer because

6. acid + magnesium carbonate $\rightarrow$ magnesium chloride + water + carbon dioxide

I write this answer because

Complete the equations and write the word equation for the following reactions:

9. $\mathrm{Mg}+\mathrm{O}_{2} \rightarrow$

10. $\mathrm{S}+\mathrm{I}_{2} \rightarrow$

\section{Appendix B1}

Activity Worksheet 1

Complete the following word equations and explain your reason for supplying the missing species. Also, state the particles (ions, atoms, molecules) that could constitute the filled-in reactant or product.

1. Nitric acid $+\ldots \ldots \ldots \ldots . . . . \rightarrow$ potassium nitrate + water

2. Metal + Acid.

\section{Appendix B2}

Activity Worksheet 4

1. Powdered zinc is added to blue aqueous copper (11) sulphate and shaken. The blue colour gradually fades to colourless, while a reddish brown precipitate is produced. Write the word equation for the observation above.

2. ................ + .................. Z Zinc nitrate + copper

i. I make these observations because

ii. What are the constituents of each of the answers that you have provided? 


\section{Appendix $C$ \\ Questions for Guided Learning Conversations}

1. Study this word chemical reaction carefully.

2. What are the basic elements that constitute each of the compounds?

3. What would be the missing parts to the chemical equation given? Explain.

4. What other answer could have been provided? Why?

5. Write out the word equation for this 'symbolic' (microscopic) representation of an equation in word form and explain why you chose those word representations.

6. Have all the participating species in the reaction been duly represented? In number?

7. * How did you find this new approach of teaching and learning? Explain further.* (* Not content-based but assesses the content-focus approach 'for', 'as' and 'of' learning) 